\title{
Design of Manufacturing Process of Mould for Die Casting by EDM Technology with the Computer Aided
}

\author{
L'. STRAKA ${ }^{1}, \mathrm{G}$. DITTRICH ${ }^{2}$ \\ ${ }^{1}$ Technical University of Kosice, Faculty of Manufacturing Technologies with a seat in Presov, Department of \\ Automobile and Manufacturing Technologies, luboslav.straka@tuke.sk \\ ${ }^{2}$ Technical University of Kosice, Faculty of Manufacturing Technologies with a seat in Presov, Department of \\ Automobile and Manufacturing Technologies, gabriel.dittrich@tuke.sk
}

Abstract. At present, we cannot imagine a modern production process without computer support. At the same time, its integral part is the implementation of advanced and highly sophisticated production processes and technologies. Their aim is first and foremost to ensure quality production of products with high economic efficiency of the production process. EDM technology is one of the currently active progressive technologies. This is a technology that in practice is characterized by high product quality. The high quality of products not only through this progressive technology, but also other, whether conventional or progressive, is difficult to achieve without computer support. The aim of the paper is therefore to demonstrate the process of manufacturing a die-casting mould using progressive EDM technology using computer support.

\section{Introduction}

At present, extremely high demands are placed not only on the quality of products, but also on the application of materials with specific properties. These increased demands on the shape, quality and materials of the products present a large number of problems in practice. One of the problems associated with these requirements is the scope of application of the machining technology used. The practical application of conventional machining technologies is usually very closely related to the machinability of the materials used. Particular limiting factors for their application are in particular the physical, mechanical and chemical properties of the material to be machined. Restrictions on achieving complicated final product contours are in many cases another limiting factor for their application [3]. At the same time, locally limited edge breaking or material removal in a certain sequence or in precisely defined layers is often required for machining. As a rule, these specific requirements require the application of multiple tools and equipment, resulting in longer machining times. The application of progressive machining technologies is therefore much more effective in the specific cases mentioned. They enable machining of highly refined high-alloy steels, carbide, etc. without any problems and at the same time create complicated shapes. [2] This is mainly due to the use of physical or physicochemical principles of material removal. All of the above-mentioned special applications of available manufacturing technologies include the production of die casting moulds [1]. Since it is almost always a prototype in mould making, computer simulation plays an important role 
here. Its aim is to prevent poor quality of the functional parts of the mould, but also to help identify possible tool collisions with the workpiece, thus preventing damage to the machine or tool.

\section{Specifics of design of mould for die casting of metals}

Die-casting technology offers a number of advantages in the foundry industry [5]. This is mainly the production of complicated shape castings with the possibility of applying special materials. They can meet the highest demands on the quality of castings, both in terms of mechanical properties and dimensional accuracy. However, these high demands can only be achieved in conjunction with a suitable design and subsequent precise production of the individual structural parts of the mould. It follows logically that the design of a die-casting mould requires in many cases a special approach. This must, however, take into account all the specificities which are imposed on that type of product. It is mainly the ability of the moulds to achieve complex casting shapes and high productivity. An important requirement is also a structural modification of the mould, which ensures a high strength of castings, e.g. by minimizing trapped gases in the melt volume. Particular demands on the properties of the finished production, but also the properties of the moulds, which, among other things, relate to its reliability and safety, are made by car manufacturers. It follows from the above-mentioned specifics for the production of castings and the construction of moulds for die-casting of metals under pressure that we can hardly imagine the design and production of the mould without modern computer technology. Prior to its production it is necessary to have a model in digital form, which significantly reduces the risk of defects in individual parts of the pressure mould. Creating a physical model is nowadays done only sporadically, because in most cases, we can fully do with the model only in digitalized form. In terms of software support, several CAD programs are used in practice [4].

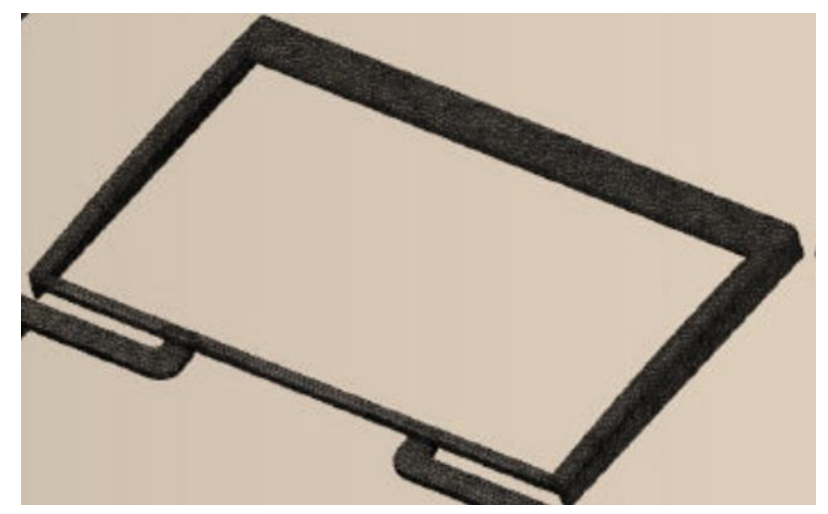

Figure 1. 3D design of casting model by CAD.

At present, there are a large number of CAD software that, in addition to the 3D design of the casting model, can also model the relevant functional parts of the die cavity for die casting. 


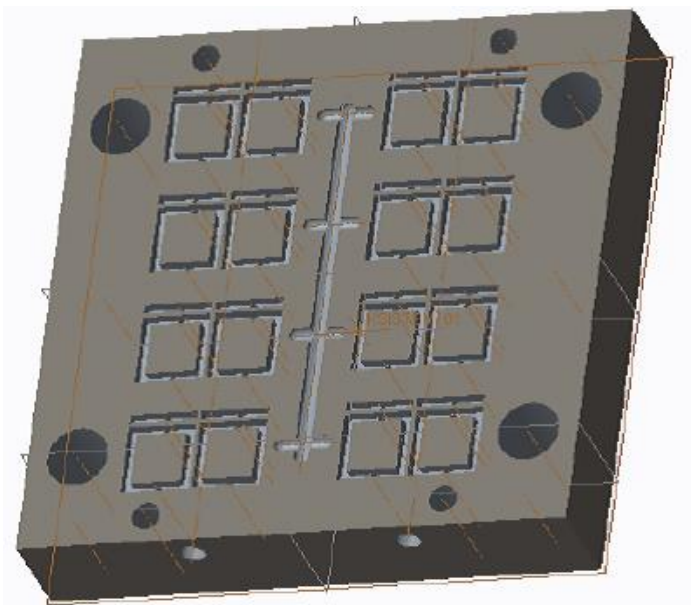

Figure 2. 3D design of functional part of mould cavity by CAD.

Other mould parts for die-casting of metal which are used to attach a fixed and movable part of a mould, its closing and opening, cooling, etc. they are already largely unified and can be selected from the appropriate software library.

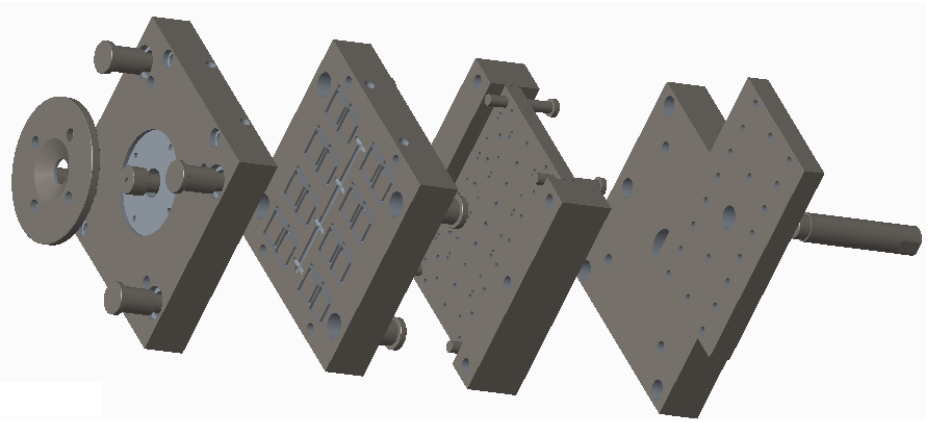

Figure 3. 3D design of auxiliary parts of moulds for die casting of metals by CAD.

Application of CAD software in engineering practice in the design of die casting moulds provides a number of advantages. The primary advantage is the automation of routine procedures, implementation of standard parts from the database, rapid prototype development, etc. An invaluable advantage of their application is also full support in the need to make the necessary changes in the construction If necessary, they allow to make relatively extensive changes in the construction of the already designed mould, or to eliminate errors that occurred only in the process of construction. The decisive advantage of their application is also the creation of countless variants, which aim to improve the process of optimization of construction solutions.

\section{3D design of tools for production of functional parts of mould cavity}

An important part of the design process of the functional part of the mould cavity itself is a detailed specification of the tools that will be used in its manufacture. In the case of the application of EDM progressive technology for the production of die casting moulds, it is a 3D design of tool electrodes [6, 11]. These tool electrodes must be designed not only for their functionality, but also for practicality, long life, but also the overall economic efficiency of their application. Also in this case, modern 
procedures require the application of computer support [7-9]. Several programs can be used for their 3D modelling. Of these, mention may be made, for example. Solid Edge, CATIA, AutoCAD, Creo 3.0, etc.

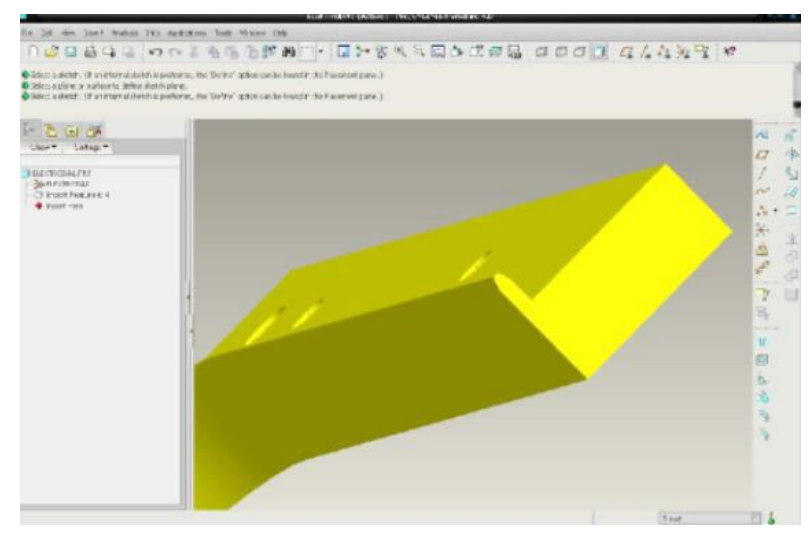

Figure 4. Design of tool electrode for EDM cavity moulds in Creo 3.0 software.

An essential part of every production process is also the creation of drawing documentation. Therefore, both for the design of individual parts of the mould and for the design of tool electrodes, it is necessary to prepare drawing documentation. For her work again, there is in practice a number of software. For example, Creo 3.0 software. allows 2D drawings to be created using a standard Drawing module from pre-created 3D models. This module also enables the creation of drawings for individual mould parts and tool electrodes as well as for their assemblies.
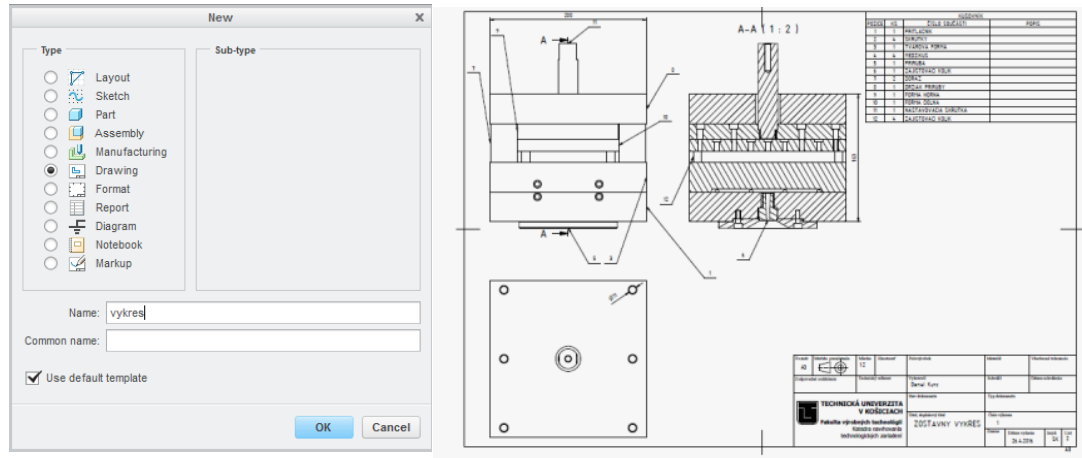

Figure 5. Creation of drawing documentation of individual parts of die casting mould.

\section{Production of die casting mould by means of EDM technology with CAD support}

One of the last steps before starting the production of the functional part of the die-casting mould is to design a process for removing individual layers of the base material by means of selected tool electrodes. Even at this stage, we can no longer do without computer support $[15,16]$. This is done in a number of steps, such as 3D designing of processed item models, defining processing technology, defining cutting conditions, simulating the processing of functional mould parts, including making necessary corrections, etc. Generally, tool path generation with full CAM support is already carried out as part of technological planning [10]. However, there are situations that require additional verification of toolpath and possibly their correction. This procedure is mainly applied in the manufacture of complex products. Alternatively, if the toolpaths are limited in addition to the 
workpiece configuration, the machine, tool and work environment configuration [17]. The final stage is therefore crucial for a correct and safe process for the production of die casting, i.e. simulation. Its task is first of all to test the correctness of the selected toolpaths, but also to set the individual technological parameters. Through it, it is possible to detect possible hidden shortcomings of the mould production process. Again, there are several software to simulate the production process [14]. In the above Creo 3.0 software. this feature is enabled by the Manufacturing module.

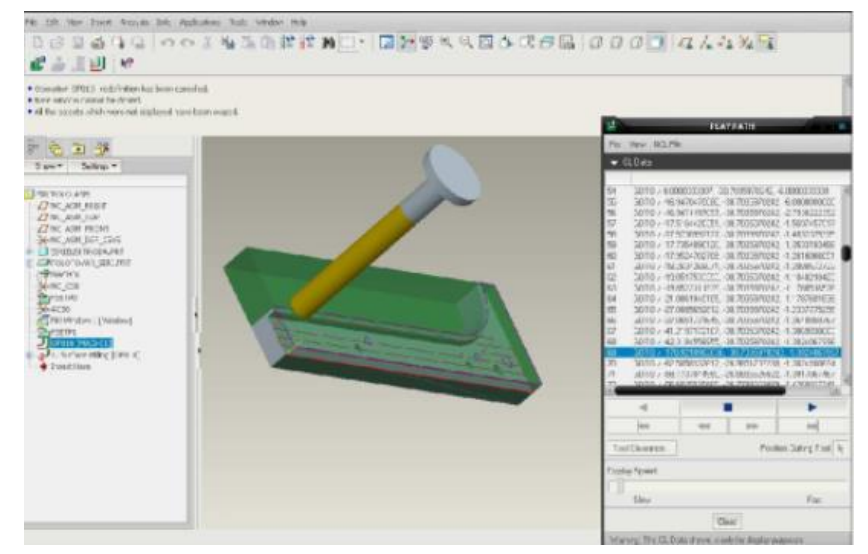

Figure 6. Simulation of production of functional part of die casting mould by EDM technology in Creo 3.0. software with the support of the Manufacturing module.

By simulating the production of the functional part of the die cavity, we can propose several alternatives of tool movement, or more precisely change selected technological parameters [17]. Based on the simulation of the production process, we obtain a number of information, including information relating to the total production time of the mould. Consequently, based on the optimization criterion chosen by us, which may be e.g. minimizing production time, maximizing production precision, etc., we have the option to choose the most suitable variant of die casting [12,13]. The result of the optimization is also an indication of the overall efficiency of the mould production process.

\section{Conclusion}

The growing demand for high-quality parts, especially for the automotive industry with short lead times, requires the application of new advanced technologies in practice. In this context, the application of existing CAD / CAM systems is gaining in importance and occupying an irreplaceable position. Its role in engineering practice is also to improve the work of engineers' efficiency of and to prevent the occurrence of mishaps As in other industries, in the foundry industry, CAD / CAM systems contribute to the constant trend of improving casting quality [18,19]. However, a high-quality casting cannot be achieved in any way by a poor-quality mould. Since die-casting moulds are almost always prototypes, it is not possible to tune their production on test samples. At the same time, simulation of the production process of the die-casting mould has its irreplaceable position mainly due to complicated repair procedures or in some cases even due to the impossibility to make corrections of a faulty execution of any of its parts. The advantage of the application of CAD / CAM systems is that in the design stage of the mould production they enable to detect possible occurrence of errors, to analyse the causes of their occurrence and to eliminate these deficiencies before the beginning of the 
production process itself. At the same time, the information obtained can be used in the subsequent optimization of the production process, thus reducing the technological preparation time of the production of the mould, the consumption of electricity, materials and the total cost of its production. For these reasons, the aim of the paper was to point out the importance of application of these highly sophisticated devices in the design and manufacture of die casting moulds using progressive EDM technology.

\section{Acknowledgments}

This work was supported by the project VEGA 1/0205/19.

\section{References}

[1] A.G. Banerjee, S.K. Gupta, Geometric algorithms for automated design of side actions in injection moulding of complex parts, Comp-Aided Des, 2007, 39, 882-897.

[2] J. Dubják, J. Pitel', M. Tóthová, Diagnostics of aluminum alloys melting temperature in high pressure casting, Key Engineering Materials, vol. 669 (2016), p. 110-117, ISSN 1013-9826.

[3] H.A. Firouzabadi, J. Parvizian, A. Abdullah, Improving accuracy of curved corners in wire EDM successive cutting, International Journal of Advanced Manufacturing Technology, 2015, 76, 447 459.

[4] M.W. Fu, The application of surface demoldability and moldability to side-core design in die and mold CAD, Comp-Aided Des, 2008, 40, 5, 567-575.

[5] J.Y.H. Fuh, S.H. Wu, K.S. Lee, Development of semi-automated die-casting die design system, Proc Instn Mech Engrs, Part B J Eng Manuf, 2002, 216, 1557-1588.

[6] S. Hašová, L. Straka, Design and verification of software for simulation of selected quality indicators of machined surface after WEDM, Academic Journal of Manufacturing Engineering, 2016, 14(2), 13-20, ISSN 1583-7904.

[7] B.D. Lee, U.H. Baek, J.W. Han, Optimization of gating-system design for die-casting of thin magnesium alloy-based multi-cavity LCD housing, J Mater Eng Perform, 2012, 21, 1893-1903.

[8] Priyadarshi, S.K. Gupta, Geometric algorithms for automated design of multi-piece permanent molds, Comp-Aided Des, 2004, 36, 241-260.

[9] R. Singh, J. Madan, A computer-aided system for multi-gate gating-system design for die-casting dies, The International Journal of Advanced Manufacturing Technology, 2019, 101(5-8), 17931806.

[10] C.D. Singh, J. Madan, A. Singh, Computer aided design of gating-system for a die-casting die, Int J Comput Appl Technol, 2013, 46, 113-127.

[11] L'. Straka, G. Dittrich, Relative electrode wear at EDM of tool steel, MM Science Journal, december 2018, 2690-2695, ISSN 1803-1269. 
International Journal of Engineering and Management Sciences (IJEMS) Vol. 5. (2020). No. 2 DOI: 10.21791/IJEMS.2020.2.7.

[12] L. Straka, I. Čorný, J. Pitel', S. Hašová, Statistical Approach to Optimize the Process Parameters of HAZ of Tool Steel EN X32CrMoV12-28 after Die-Sinking EDM with SF-Cu Electrode, Metals, 2017, vol. 7, no. 2, p. 1-22.

[13] A.T. Salcedo, I.P. Arbizu, C.J. Luis Pérez, Analytical modelling of energy density and optimization of the EDM machining parameters of inconel 600, Metals, 2017, vol. 7, no. 5, p. 1-21.

[14] T.R. Vijayaram, Numerical simulation of casting solidification in permanent metallic molds, Journal of Materials Processing Technology, 2006, 178, 29-33.

[15] Y.K. Woon, K.S. Lee, Development of a die design system for die casting, Adv Manuf Technol, 2004, 23(5-6), 399-411.

[16] X.G. Ye, K.S. Lee, J.Y.H. Fuh, Y.F. Zhang, A.Y.C. Nee, Automatic initial design of injection mould, Int J Mater Prod Tech, 200, 15, 503-517.

[17] W. Zhang, X. Wang, Simulation of the inventory cost for rotable spare with fleet size impact, Academic Journal of Manufacturing Engineering: Editura Politechnica, 2017, vol. 15, no. 4, p. 124-132, ISSN 1583-7904.

[18] Y. Zhao, K. Ridgway, A.M.A. Al-Ahmari, Integration of CAD and a cutting tool selection system, Computers and Industrial Engineering, 2017, 42, 17-34.

[19] Z. Zhao, J.J. Shah, Domain independent shell for DfM and its application to sheet metal forming and injection molding, Computer-Aided Design, 37, 2005, 881-898. 